\title{
Use of immunoblotting to identify antigenic differences between the yeast and mycelial phases of Candida albicans
}

\author{
JAMES P BURNIE, ${ }^{*}$ RUTH C MATTHEWS, $\dagger$ ANDREW FOX, $\ddagger$ SOAD TABAQCHALI $\dagger$ \\ From the *Department of Medical Microbiology, The London Hospital Medical College, London E1, the \\ $\dagger$ Department of Medical Microbiology, St Bartholomew's Hospital, West Smithfield, London EC1, and the \\ $\ddagger$ Public Health Laboratory, Withington Hospital, Manchester
}

SUMMARY Western blotting was applied to the analysis of Candida albicans in the yeast and mycelial phases in an attempt to recognise mycelial specific antigens which might be of serodiagnostic value. The antisera were prepared in rabbits by immunising them with pressates of $C$ albicans type A NCTC 3153 in the yeast phase or the mycelial phase. These were blotted against $C$ albicans in the yeast and mycelial phases and the yeast phase of $C$ parapsilosis, $C$ krusei, $C$ tropicalis, and Torulopsis glabrata. Cross reactivity was greatest against $C$ parapsilosis. One yeast specific mannoprotein was identified with a molecular weight of 49000 . No mycelial specific antigens could be identified.

The profusion of published work on the serodiagnosis of systemic candidosis is a reflection of the difficulty in defining an antigen-antibody system which characterises the disease. Part of the difficulty lies in the fact that Candida albicans can exist in a yeast or a mycelial phase in vivo.' Most of the antigens used in serological tests are derived from the yeast phase, whereas the mycelial form is more typical of deep seated infections.' Thus the identification of mycelial specific antigens might form the basis of a serological test which could reliably differentiate between invasive disease and colonisation. Syverson et al, ${ }^{2}$ using crossed immunoelectrophoresis, showed six antigens which were unique to each phase. Manning et al, ${ }^{3}$ using two dimensional electrophoresis, failed to show an antigen unique to the mycelial form.

By combining immunoblotting with sodium dodecyl sulphate polyacrylamide gel electrophoresis (SDS PAGE), it is possible to characterise the specific antibody response to a particular antigen in a complex mixture of antigens. The limits of antigen detection are as low as $100 \mu \mathrm{g}$ of protein. ${ }^{4}$ In the present study antisera to both the yeast and mycelial phases of $C$ albicans were used to detect antigen differences between them. Using an enzyme substrate system the colour produced was proportional

Accepted for publication 5. February 1985 to the amount of antibody bound. The serological response to any particular protein could therefore be semiquantified using a Chromoscan 3 densitometer.

Candidal antigens prepared by fragmentation at $-70^{\circ} \mathrm{C}$ were used both to immunise the rabbits and to prepare the gels. Similar antigens have been used to investigate skin reactivity ${ }^{5}$ and as the basis of an enzyme linked immunoassay for the detection of $C$ albicans cytoplasmic antigen. ${ }^{6}$ The antisera were also immunoblotted against other candidal species which commonly cause disease. This gives some idea of the immunological cross reactivity between species, which is reflected in the ability of serological tests designed to diagnose candidosis to detect these other species.

\section{Material and methods}

PREPARATION OF PRESSATES

The following yeasts were cultured: $C$ albicans type A (NCTC 3153), C parapsilosis (NCPF 3104), C krusei (NCPF 3101), C tropicalis (NCPF 3111), and Torulopsis glabrata (NCPF 3240). Each was grown on neutral glucose peptone agar (2\% glucose) at $26^{\circ} \mathrm{C}$ overnight and then harvested in distilled water and washed three times.

The mycelial phase of $C$ albicans was grown in a defined minimal medium supplemented with amino 
acids as described by Lee et al. ${ }^{7}$ Cultures were shaken in a gyratory incubator at about $200 \mathrm{rpm}$ at $37^{\circ} \mathrm{C}$ for $12 \mathrm{~h}$. Cells grown under these conditions were in the mycelial phase, although it is not possible completely to eliminate the yeast form. ${ }^{7}$

Cells were fragmented in an Xpress (LKB, Bromma, Sweden) at a pressure of $200 \mathrm{mPa}$. The press was frozen at $-70^{\circ} \mathrm{C}$ overnight and then loaded with yeast and placed within plastic bags in a $70 \%$ methanol bath containing cardice for $30 \mathrm{~min}$. The plastic bags prevented methanol from penetrating into the chamber containing the yeast.

The press was taken from the bath, the plastic bags were removed, and $200 \mathrm{mPa}$ pressure was exerted. The process was repeated three times to obtain $90 \%$ or more disruption of cells. The disintegrated cells were removed from the press and centrifuged at $38000 \mathrm{~g}$ for $1 \frac{1}{2} \mathrm{~h}$ at $4^{\circ} \mathrm{C}$. The supernatant was filtered through a $0.22 \mu \mathrm{m}$ Millipore membrane (Millex) to ensure sterility. Protein concentration was estimated as described by Lowry $e t$ $a l .{ }^{8}$ The supernatants, described as pressates, were stored at $-20^{\circ} \mathrm{C}$ before use.

PREPARATION OF MANNAN DEPLETE EXTRACTS Concanavalin A Sepharose 4B columns (Pharmacia) were used to extract the mannan containing proteins from the pressates. ${ }^{9}$ By measuring the protein concentration of the pressate before running it through the column and afterwards, the proportion of yeast and mycelial phase proteins containing mannan could be estimated. The column was eluted with 0.2 $\mathbf{M} \alpha$-methylmannoside in $0 \cdot 1 \mathrm{M}$ sodium phosphate

Table 1 Densitometry of rabbit antiyeast and antimycelial antibody immunoblotted against the yeast phase antigen

\begin{tabular}{|c|c|c|c|}
\hline $\begin{array}{l}\text { Band } \\
\text { number }\end{array}$ & $\begin{array}{l}\text { Molecular weight } \\
\text { (kilodaltons) }\end{array}$ & $\begin{array}{l}\text { Antiyeast } \\
\text { antibody }\end{array}$ & $\begin{array}{l}\text { Antimycelial } \\
\text { antibody }\end{array}$ \\
\hline $\begin{array}{r}1 \\
2 \\
3 \\
4 \\
5 \\
6 \\
7 \\
8 \\
9 \\
10 \\
11 \\
12 \\
13 \\
14 \\
15 \\
16 \\
17 \\
18 \\
19 \\
20 \\
21\end{array}$ & $\begin{array}{r}116 \\
100 \\
92 \\
84 \\
80 \\
74 \\
69 \\
66 \\
63 \\
59 \\
57 \\
56 \\
55 \\
51 \\
50 \\
49 \\
47 \\
45 \\
41 \\
34 \\
33\end{array}$ & $\begin{array}{l}197(10) \\
112(30) \\
178(20) \\
190(5) \\
202(10) \\
157(20) \\
237(13) \\
151(17) \\
100(10) \\
200(5) \\
235(3) \\
100(15) \\
163(20) \\
196(5) \\
198(3) \\
184(10) \\
118(5) \\
123(20) \\
170(13) \\
222(30) \\
217(10)\end{array}$ & $\begin{array}{l}128(15) \\
108(30) \\
230(5) \\
176(15) \\
138(5) \\
152(15) \\
107(20) \\
146(30) \\
179(5) \\
104(5)\end{array}$ \\
\hline
\end{tabular}

Values (in mm) given as mean (SD) of five immunoblots.
$1 \mathrm{M}$ sodium chloride buffer according to the technique of Kennedy and Rosevear. ${ }^{10}$

\section{RABBIT IMMUNISATION}

New Zealand white rabbits were injected intravenously at weekly intervals with $25 \mathrm{mg}$ of pressate. They were bled before the first injection to ensure that they were antibody free. Serum obtained after the fourth injection at 21 days was used in subsequent experiments. The titre of each antiserum was $1 / 10000$ by whole cell agglutination and strongly positive at $1 / 8$ using countercurrent immunoelectrophoresis."

\section{SDS-PAGE}

Pressates and the mannan deplete extract were solubilised in $2.6 \%$ SDS and $1.3 \%$ 2-mercaptoethanol at $100^{\circ} \mathrm{C}$ for $5 \mathrm{~min}$. Electrophoresis of these preparations was carried out using $10 \%$ polyacrylamide gels in a discontinuous buffer system. ${ }^{12}$ Fifty micrograms of protein was applied to each well. Molecular weight standards were: myosin, 200000 ; $\beta$-galactosidase, 116 250; phosphorylase B, 92 500; bovine serum albumin, 66 200; ovalbumin, 45 000; carbonic anhydrase, 31000 ; soybean trypsin inhibitor, 21 500; and lysozyme, 14400.

\section{WESTERN BLOTS}

Proteins were transferred ${ }^{4}$ on to nitrocellulose paper (Bio-Rad Laboratories, Richmond, California) in buffer containing $25 \mathrm{mM}$ Tris, $192 \mathrm{mM}$ glycine, and $20 \%$ methanol ( $\mathrm{pH} \mathrm{8 \cdot 3)}$. Transfer was performed at $25^{\circ} \mathrm{C}$ with a current of $350 \mathrm{~mA}$ for $1 \frac{1 / 2}{\mathrm{~h}}$ in a Bio-

Table 2 Densitometry of rabbit antiyeast and antimycelial antibody immunoblotted against the mycelial phase antigen

\begin{tabular}{|c|c|c|c|}
\hline $\begin{array}{l}\text { Band } \\
\text { number }\end{array}$ & $\begin{array}{l}\text { Molecular weight } \\
\text { (kilodaltons) }\end{array}$ & $\begin{array}{l}\text { Antiyeast } \\
\text { antibody }\end{array}$ & $\begin{array}{l}\text { Antimycelial } \\
\text { antibody }\end{array}$ \\
\hline $\begin{array}{l}1 \\
2 \\
3 \\
4 \\
5 \\
6 \\
7 \\
8 \\
9 \\
10 \\
11 \\
12 \\
13 \\
14 \\
15 \\
16 \\
17 \\
18 \\
19 \\
20 \\
21\end{array}$ & $\begin{array}{r}116 \\
100 \\
92 \\
84 \\
80 \\
74 \\
69 \\
66 \\
63 \\
59 \\
57 \\
56 \\
55 \\
51 \\
50 \\
49 \\
47 \\
45 \\
41 \\
34 \\
33\end{array}$ & 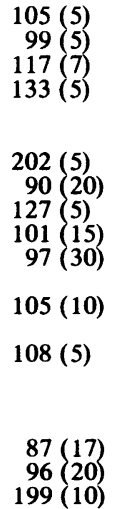 & $\begin{array}{l}161(20) \\
113(10) \\
115(10) \\
112(5) \\
203(17) \\
166(20) \\
128(5) \\
168(10) \\
138(20) \\
172(15) \\
176(7) \\
124(5) \\
\\
124(30) \\
120(15) \\
126(30) \\
166(13) \\
230(30)\end{array}$ \\
\hline
\end{tabular}


Table 3 Immunoblotting of rabbit antiyeast and antimycelial sera against mannan deplete $C$ albicans yeast phase extract

\begin{tabular}{|c|c|c|}
\hline \multirow{2}{*}{$\begin{array}{l}\text { Band } \\
\text { number }\end{array}$} & \multicolumn{2}{|c|}{ Mannan deplete extract } \\
\hline & Antiyeast & Antimycelial \\
\hline 1 & + & + \\
\hline 2 & + & + \\
\hline 3 & & \\
\hline 4 & & \\
\hline 5 & + & + \\
\hline 6 & + & + \\
\hline 7 & + & + \\
\hline 8 & + & + \\
\hline 9 & & \\
\hline 10 & + & + \\
\hline 11 & + & + \\
\hline 12 & + & + \\
\hline 13 & + & + \\
\hline 14 & + & + \\
\hline 15 & & \\
\hline 16 & $\mathrm{Tr}^{*}$ & \\
\hline 17 & $\pm \dagger$ & \pm \\
\hline 18 & \pm & \pm \\
\hline 19 & \pm & \pm \\
\hline 20 & & \\
\hline $2 !$ & + & + \\
\hline
\end{tabular}

*Trace consistently present in the five immunoblots examined. †Not consistently present in the five immunoblots examined.
Rad Trans-Blot cell. Free protein sites were saturated by incubation in $3 \%$ bovine serum albumin (Sigma) in buffered saline $(0.9 \% \mathrm{NaCl}$ and $10 \mathrm{mM}$ Tris, $\mathrm{pH} 7.4)$ at $4^{\circ} \mathrm{C}$ overnight. The nitrocellulose was then incubated at $25^{\circ} \mathrm{C}$ for $2 \mathrm{~h}$ with antiyeast or antimycelial rabbit antiserum, diluted $1 / 100$ in $3 \%$ bovine serum albumin and $0.05 \%$ Tween 20 (Bio$\mathrm{Rad}$ ) in buffered saline. After washing five times over $30 \mathrm{~min}$ in $0.9 \%$ saline and $0.05 \%$ Tween 20 , the nitrocellulose was incubated for $1 \mathrm{~h}$ at $25^{\circ} \mathrm{C}$ with alkaline phosphatase goat antirabbit IgG (Sigma). The conjugate was diluted $1 / 1000$ immediately before use in $3 \%$ bovine serum albumin in buffered saline. After washing, as above, the nitrocellulose was incubated for $15 \mathrm{~min}$ at $25^{\circ} \mathrm{C}$ in a freshly prepared and filtered mixture of equal volumes of naphthol AS-MX phosphate (Sigma; $0.4 \mathrm{mg} / \mathrm{ml}$ in distilled water) and fast red TR salt (Sigma; $6 \mathrm{mg} / \mathrm{ml}$ in $0.2 \mathrm{M}$ Tris, $\mathrm{pH} 8.2$ ) as described by $\mathrm{O}^{\prime}$ Connor and Ashmann. ${ }^{13}$ Antigen-antibody binding was semiquantified a densitometer (Chromoscan 3, Joyce Loebl).

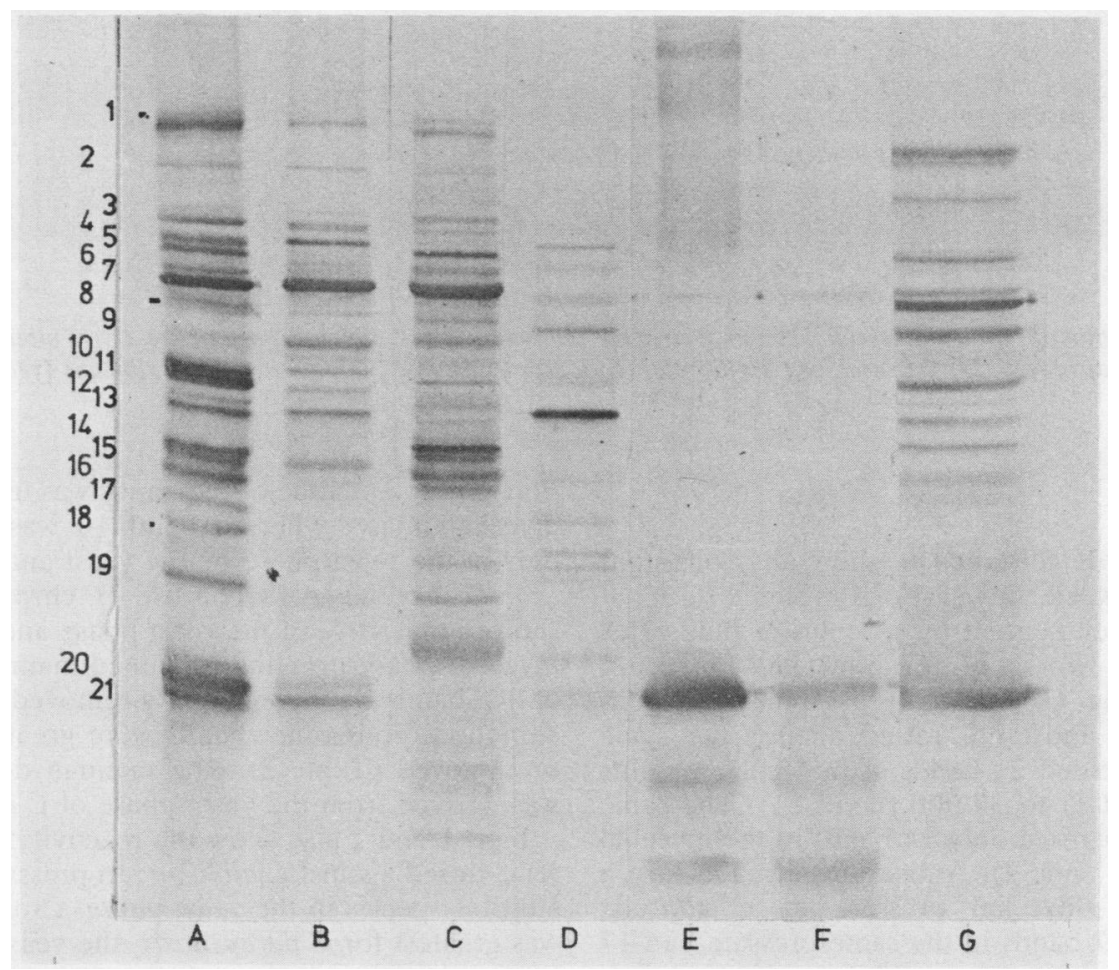

Fig. 1 Immunoblot of rabbit antiyeast serum against the following: (A) $C$ albicans yeast phase, (B) C albicans mycelial phase, (C) C parapsilosis, (D) C krusei, (E) $T$ glabrata, (F) $C$ tropicalis, $(G)$ mannan deplete $C$ albicans (yeast phase). 


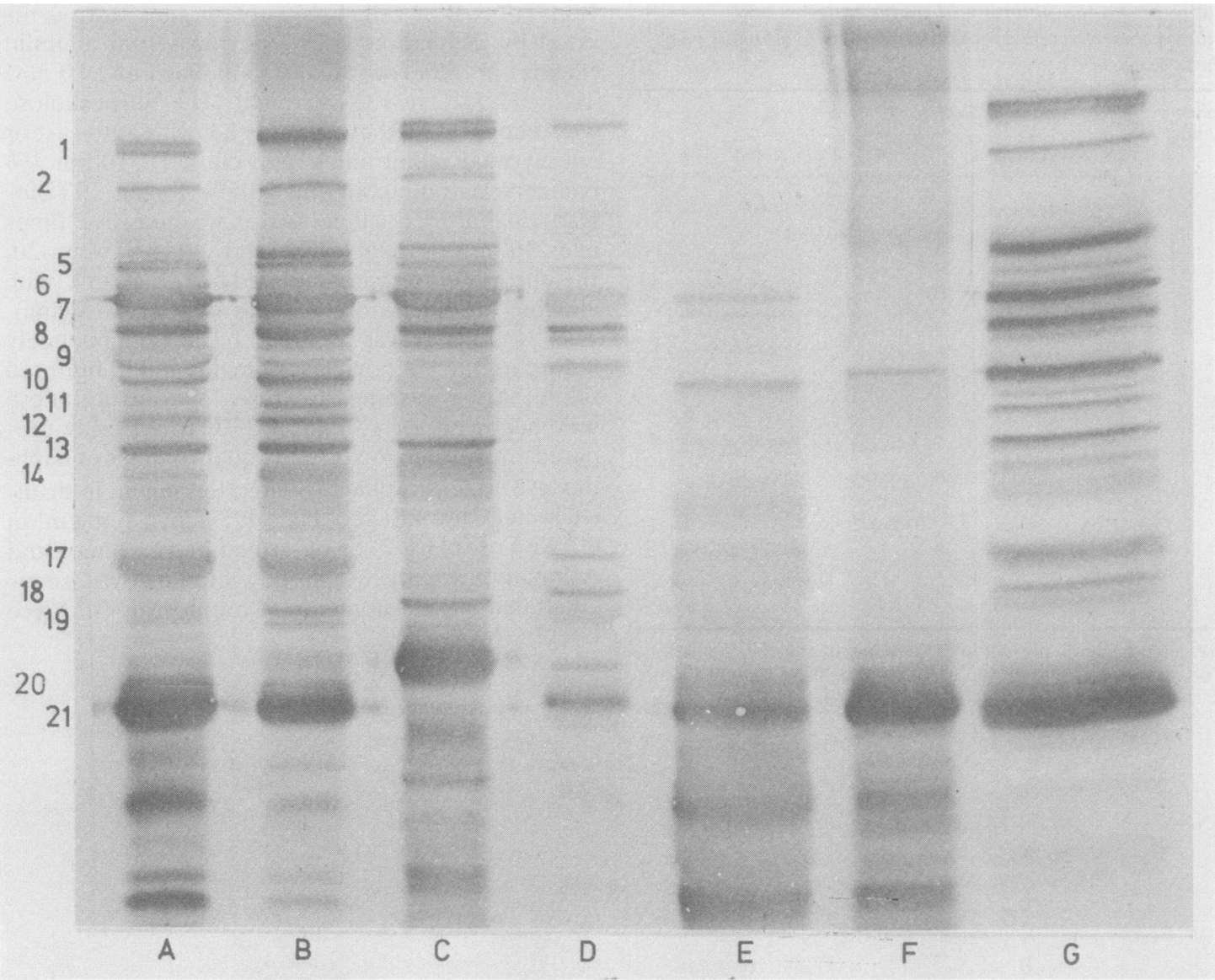

Fig. 2 Immunoblot of rabbit antimycelial serum against the following: $(A) C$ albicans yeast phase, $(B) C$ albicans mycelial phase, (C) C parapsilosis, (D) C krusei, (E) $T$ glabrata, (F) C tropicalis, $(G)$ mannan deplete $C$ albicans (yeast phase).

\section{Results}

The SDS PAGE gel failed to show any consistent difference between the yeast and mycelial forms of $C$ albicans when stained by Coomassie blue. This confirms the work of Chaffin and Stocco. ${ }^{14}$ Immunoblotting $C$ albicans yeast phase antigens against rabbit antiserum raised against the same yeast phase yielded 21 bands of molecular weights 116000 (band 1) to 33000 (band 21). The same antiserum recognised only 14 bands in the mycelial phase (Tables 1 and 2). Antiserum raised against a predominantly mycelial pressate of $C$ albicans reacted with 17 bands in the same pressate and 17 bands in the yeast pressate. Eleven of the bands were recognised by both antisera in both the yeast and the mycelial phases. Two of these (bands 9 and 20) were absent from the mannan deplete prepara- tion (Table 3). None of the bands was unique to the mycelial phase, whereas band 16 was detectable only in the yeast phase by the yeast antiserum.

Concanavalin A Sepharose B chromatography showed that $10 \%$ of the yeast phase and $6 \%$ of the mycelial phase proteins contained mannan. A total of five bands were consistently removed by mannan depletion. Four other bands were greatly depleted or removed (Table 3 ). The mannan deplete form was derived from the yeast phase of $C$ albicans.

Figs. 1 and 2 also show the reactivity of the antisera, raised against $C$ albicans, to pressates of nonalbicans species in the yeast phase. Cross reactivity was greatest for $C$ parapsilosis, the yeast antiserum recognising 20 bands and mycelial antiserum 14 bands of molecular weight $116000-37000$. The 33000 molecular weight protein was prominent in most species, with the exception of $C$ parapsilosis. 
Bands of molecular weights less than 33000 were not consistent and probably represent small fragments of mannoproteins.

\section{Discussion}

Previous studies ${ }^{2314-17}$ attempting to identify mycelial specific antigens have given conflicting results. In this paper Western blotting was used because of its sensitivity ${ }^{4}$ and ability to break down a pool of antigens into its composite parts. With rabbit antisera raised against yeast, 21 antigenic bands were identified in the yeast phase of $C$ albicans. Ten of these were also present in the mycelial phase. At least one mannan containing band (number 16 of molecular weight 49000 ) appeared to be unique to the yeast phase. Yeast specific proteins have been described by others. ${ }^{23}$ In contrast, all 16 bands in the mycelial pressate recognised by the antimycelial serum were recognisable in the yeast phase. There was therefore no evidence of any mycelial specific antigens.

The yeast phase of $C$ albicans can readily be prepared without any mycelial forms being present. In contrast, mycelial phases inevitably contain a small proportion of yeast cells. ' It is impossible to remove these. As a result, yeast specific antigens will be detectable in the electrophoresed "mycelial" pressate and the anti-"mycelial" serum may contain some antiyeast activity. This probably accounts for anomalous results such as bands 3 and 15 (present in both pressates but detected only by antiyeast serum) and band 6 (present only in the yeast phase but detected by both sera) and bands 4, 5, 12, 14, 17, and 18 . Such bands may represent yeast specific proteins since, had they been common to both phases, they should be detectable with both antisera in both pressates. Mycelial specific antigens would not be masked in this manner, however, as there is no mycelial contamination of the yeast phase.

Mannan depletion removed bands 3, 4, 9, 15, and 20 consistently, which suggests that they contain appreciable amounts of mannan. Ten percent of the yeast phase and $6 \%$ of the mycelial phase proteins contained mannan. This is consistent with previous estimates of the mannan content of pressates ${ }^{5}$ and biochemical data which show that the yeast phase contains more mannan. ${ }^{18}$ Bands $16-19$ were less consistently removed by mannan depletion, suggesting a much lower mannan content. The more mannan rich bands tend to be preferentially absorbed by the column.

Both antiyeast and antimycelial serum samples cross reacted with the yeast phases of various nonalbicans species. This was most extensive between the antiyeast serum and $C$ parapsilosis ( 20 bands), whereas only 14 bands were recognised by the antimycelial serum. Bands occurring in the same position as those in $C$ albicans are not necessarily the same proteins, although a protein of molecular weight 33000 was prominent in most species except $C$ parapsilosis. The mannan containing proteins with molecular weights less than 33000 showed a high degree of cross reactivity between species. They are probably the low molecular weight fragments of larger proteins and react with the $C$ albicans antisera because of their high mannan content. Although the mannoproteins constitute only a small proportion of the pressate, there can be no doubt of their immunogenicity. ${ }^{19}$ Excluding this activity, we found that cross reactivity was greater with $C$ parapsilosis and $C$ krusei than with $C$ tropicalis and $T$ glabrata among bands of equal or greater than 33000 molecular weight.

Hasenclever $e t a^{20}$ found that $C$ albicans type A and $C$ tropicalis were antigenically identical using whole cell agglutination. Whole cell agglutination, however, examines only those antigens on the external surface of the fungal cell. These contain mannan. The ultracentrifugation step of the preparation of a pressate is designed to remove as many as possible of such antigens, the sticky mannan being left in the pellet. It is therefore not surprising that immunoblotting suggests considerable cross reactivity between the small mannoproteins but only limited antigenic similarity between the other proteins.

Crossed immunoelectrophoresis has suggested the presence of mycelial specific antigens, ${ }^{2}{ }^{16}$ but this may reflect the lower sensitivity of this assay system. ${ }^{16}$ Smail and Jones, ${ }^{16}$ using indirect immunofluorescence, showed that certain antigens were concentrated on the germ tubes of the mycelial phase but were also present in tiny amounts on the yeast surface. Perhaps these same antigens are present in relatively large amounts intracellularly in the yeast phase and so methods such as ours which disrupt the cells before blotting against rabbit antisera do not recognise them as unique to the mycelial phase. Consistent with this, Manning and Mitchell ${ }^{3}$ failed to show any mycelial specific antigens when they disrupted their cells before two dimensional electrophoresis. It is possible that mycelial specific antigens are lost during solubilisation before electrophoresis since heat labile, germ tube specific antigens have been described by Sundstrom and Kenny. ${ }^{17}$ By means of indirect immunofluorescence, they also showed that these antigens were destroyed by dithiothreitol. In contrast, dithiothreitol extracts were used by Smail and Jones to show antigens that were preferentially expressed on the surface of germ tubes. ${ }^{16}$ It is possible that the mycelial phase pro- 
duced in vivo is antigenically different from that formed in vitro, although they are morphologically similar.

In conclusion, Western blotting showed multiple yeast specific antigens but no mycelial specific antigens. Any antigen which was specific to the mycelial phase should be recognised by the antimycelial serum and would not be detectable in the yeast pressate or by the antiyeast serum. The absence of such an antigen using this highly sensitive technique mitigates against any need to use the mycelial phase as the basis of a serological test for invasive candida.

\section{References}

' Munoz M, Estes G, Kilpatrick M, Di Salvo A, Virella G. Purification of cytoplasmic antigens from the mycelial phase of Candida albicans: possible advantages of its use in Candida serology. Mycopathologia 1980;72:47-53.

${ }^{2}$ Syverson RE, Buckley HR, Campbell CC. Cytoplasmic antigens unique to the mycelial or yeast phase of Candida albicans. Infect Immun 1975;12:1184-8.

${ }^{3}$ Manning M, Mitchell TG. Morphogenesis of Candida albicans and cytoplasmic proteins associated with differences in morphology, strain or temperature. J Bacteriol 1980;144:258-73.

4 Towbin H, Staehelin T, Gordon J. Electrophoretic transfer of proteins from polyacrylamide gels to nitrocellulose sheets: Procedure and some applications. Proceedings of the National Academy of Science 1979;76:4350-4.

${ }^{5}$ Longbottom JL, Brighton WD, Edge G, Pepys J. Antibodies mediating type I skin test reactions to polysaccharide and protein antigens of Candida albicans. Clinical Allergy 1976; 6:41-9.

- Araj GF, Hopfer RL, Chestnut S, Fainstein V, Bodey GP. Diagnostic value of the enzyme-linked immunosorbent assay for detection of Candida albicans cytoplasmic antigen in sera of cancer patients. J Clin Microbiol 1982;16:46-52.

' Lee KL, Buckley HR, Campbell CC. An amino acid liquid synthetic medium for development of mycelial and yeast forms of Candida albicans. Sabouraudia 1975;13:148-53.

${ }^{*}$ Lowry OH, Rosebrough NJ, Farr AL, Randall RJ. Protein measurement with the folin phenol reagent. J Biol Chem 1951;193:265-75.
" Ellsworth JH, Reiss E, Bradley RL, Chmel H, Armstrong D. Comparative serological and cutaneous reactivity of candidal cytoplasmic proteins and mannan separated by affinity for concanavalin A. J Clin Microbiol 1977;5:91-9.

${ }^{10}$ Kennedy JF, Rosevear A. An assessment of the fractionation of carbohydrates on concanavalin A Sepharose 4B by affinity chromatography. Journal of the Chemical Society Perkin 1973;I:2041-6.

"Kozinn PJ, Taschdjian CL, Goldberg PK, et al. Efficiency of serologic tests in the diagnosis of systemic candidiasis. Am J Clin Pathol 1978; 70:893-8.

${ }^{12}$ Laemmli UK. Cleavage of structural proteins during the assembly of the head of bacteriophage T4. Nature 1970;227:680-5.

${ }^{13}$ O' Connor CG, Ashman LK. Application of the nitrocellulose transfer technique and alkaline phosphatase conjugated antiimmunoglobulin for determination of the specificity of monoclonal antibodies to protein mixtures. J Immunol Methods 1982;54:267-71.

${ }^{14}$ Chaffin WL, Stocco DM. Cell Wall proteins of Candida albicans. Can J Microbiol 1983;29:1438-44.

is Greenfield RA, Jones JM. Purification and characterisation of a major cytoplasmic antigen of Candida albicans. Infect Immun 1981;30:78-89.

${ }^{16}$ Smail EH, Jones JM. Demonstration and solubilization of antigens expressed primarily on the surfaces of Candida albicans germ tubes. Infect Immun 1984;45:74-81.

17 Sundstrom PM, Kenny GE. Characterization of antigens specific to the surface of germ tubes of Candida albicans by immunofluorescence. Infect Immun 1984;43:850-5.

${ }^{18}$ Schwartz DS, Larsh HW. An effective medium for the selective growth of yeast or mycelial forms of Candida albicans: biochemical aspects of the two forms. Mycopathologia 1980; 70:67-75.

${ }^{14}$ Lehmann PF, Reiss E. Comparison by ELISA of serum antiCandida albicans mannan IgG levels of a normal population and in diseased patients. Mycopathologia 1980;70:89-93.

${ }^{20}$ Hasenclever HF, Mitchell WO. Antigenic studies of Candida. 1. Observation of two antigenic groups in Candida albicans. $J$ Bacteriol 1961;82:570-3.

Requests for reprints to: Dr JP Burnie, Department of Medical Microbiology, The London Hospital Medical College, Turner Street, London E1, England. 